\title{
CARDIOVASCULAR MANIFESTATIONS OF CHILDHOOD ONSET HYPOTHYROIDISM
}

\author{
Abhamoni Baro1, Sumitra Venkatesh², Shakuntala S. Prabhu
}

${ }^{1}$ Senior Resident, Department of Paediatrics, Bai Jerbai Wadia Hospital for Children.

${ }^{2}$ Assistant Professor, Department of Paediatrics, Division of Cardiology, Bai Jerbai Wadia Hospital for Children, Mumbai, Maharashtra. 3 Professor and HOD, Department of Paediatrics, Division of Cardiology, Bai Jerbai Wadia Hospital for Children, Mumbai, Maharashtra.

ABSTRACT

\section{BACKGROUND}

Thyroid hormones exert a direct cellular effect on almost all the tissues of the body including the heart. Limited studies are available in the country to assess the various cardiovascular parameters in hypothyroid children and the impact of treatment on these parameters.

\section{MATERIALS AND METHODS}

32 newly diagnosed hypothyroid paediatric patients who presented to B. J. Wadia Hospital for Children were studied over a period of 18 months. They were clinically evaluated and underwent relevant investigations, including thyroid profile estimation, cardiac evaluation using electrocardiography (ECG) and 2D - Echocardiography/colour Doppler. 29 patients were reviewed after 3 months of treatment.

\section{RESULTS}

The majority (18 cases $-56.3 \%$ ) of the patients were above 10 years with a female preponderance ( $68.8 \%$ females). Mean value of TSH and Free T4 were $205.58 \pm 267.33 \mu \mathrm{IU} / \mathrm{mL}$ and $0.67 \pm 0.37 \mathrm{ng} / \mathrm{dL}$ respectively. Symptoms and signs were significantly common with TSH (thyroid stimulating hormone) above $50 \mu \mathrm{g} / \mathrm{mL}$. Dyslipidaemia was found in 22 (68.75\%) cases. The most common ECG abnormality observed was prolonged PR interval in $14(43.8 \%)$ cases and the most common echocardiographic finding was septal hypertrophy, seen in 16 (50\%) cases, followed by left ventricular posterior wall hypertrophy (LVPW) (43.8\%), LV dilatation (25\%), pericardial effusion (25\%) and cardiac dysfunction in 4 cases. At 3 months follow-up of 29 subjects, significant improvement of all the deranged parameters was noted with the achievement of euthyroidism.

\section{CONCLUSION}

It was concluded that children with hypothyroidism have significant cardiovascular abnormalities proportional to TSH level and these resolve completely with treatment. Hence, early diagnosis with optimal treatment reduces the cardiac morbidity in these children.

\section{KEYWORDS}

Hypothyroidism, Echocardiography, Paediatric.

HOW TO CITE THIS ARTICLE: Baro A, Venkatesh S, Prabhu SS. Cardiovascular manifestations of childhood onset hypothyroidism. J. Evolution Med. Dent. Sci. 2017;6(91):6464-6469, DOI: 10.14260/jemds/2017/1405

\section{BACKGROUND}

Hypothyroidism is one of the most common endocrine abnormalities in children. Thyroid hormone exerts direct cellular effect on almost all the tissues of the body including heart which has been recognised for several decades. ${ }^{1}$

The cardiac effects of hypothyroidism depend on the severity and duration of the disease and can range from subtle abnormalities to overt and easily recognisable manifestations. The available data suggests that the direct effect of thyroid hormone on the heart is primarily via a change in protein synthesis. The effect on cardiac contractility also appears to be mediated in part by changes in intracellular calcium handling. ${ }^{2}$ Hypothyroidism is known to be associated with both structural and functional alterations in the myocardium. Hypothyroidism is also

'Financial or Other Competing Interest': None.

Submission 11-08-2017, Peer Review 11-11-2017,

Acceptance 17-11-2017, Published 27-11-2017.

Corresponding Author:

Abhamoni Baro,

Flat No. 4B, Block B, $4^{\text {th }}$ Floor

Mainaak Greens Apartments,

Near Ayaakar Bhawan,

G. S. Roas, Guwahati-781005, Assam.

E-mail:drabhamonibaro@gmail.com

DOI: $10.14260 /$ jemds $/ 2017 / 1405$ associated with dyslipidaemia and an increased risk of atherosclerosis. Extrapolation from studies carried out in adults must be made with great caution because of structural and functional differences between the adult and paediatric myocardial tissue. Early diagnosis and treatment of hypothyroidism can decrease cardiac morbidity and be an additional benefit to the screening program for hypothyroidism. This prompted us to study the effects of hypothyroidism on the cardiovascular system in the paediatric population at a tertiary care hospital for children, with established divisions of Paediatric Endocrinology and Cardiology.

\section{MATERIALS AND METHODS}

This study was a prospective, observational, cohort study done in a tertiary care centre (Bai Jerbai Wadia Hospital for Children) in the city of Mumbai. 32 newly diagnosed hypothyroid patients with age ranging from day 4 to 15 years who have not received treatment were included in this study. Informed consent was obtained from the parents of all included children and the proposal was approved by the Institutional Ethics Committee. The study was conducted from June 2012 to November 2013. Both Congenital and acquired hypothyroid patients were included. Congenital and/or acquired heart disease and cardiovascular 
abnormality due to other causes were excluded. Detailed history and thorough physical examination including heart rate, blood pressure, pulse oximetry and detailed cardiovascular system examinations were done. All findings were adjusted for age, sex, and gender. Laboratory evaluation included thyroid function test (radioimmunoassay), Lipid Profile (automated biochemical assay), ECG, 2D Echocardiography/colour Doppler. The diagnosis of hypothyroidism was made on the basis of clinical features coupled with elevated serum TSH (Thyroid stimulating hormone) level and low free thyroxine (fT4) level. Cases were divided into two groups based on TSH levels i.e. group A-TSH below $50 \mu \mathrm{IU} / \mathrm{mL}$ and Group B with TSH above $50 \mu \mathrm{IU} / \mathrm{mL}$. QTc (corrected QT interval) was calculated by the Bazett's formula and a cut-off of 0.44 seconds (age above 6 months) and 0.45 seconds (first 6 months of life). 2DEchocardiography/Colour Doppler was done with a state-ofart, stand-alone 2D-Echocardiography machine Philips iE 33 and this was carried out by a single trained paediatric cardiologist attached to the Cardiology division of the hospital. Conventional echocardiographic measurements were done according to the American Society of Echocardiography Pediatric guidelines. ${ }^{3}$ To analyse myocardial involvement: LVPW (Left Ventricular Posterior Wall Thickness) and IVS (Interventricular septal thickness) measurements were taken and the Z-score was calculated considering the Body Surface Area (BSA) to minimise effects of age, gender, and overweight status. The dimensions of the heart were assessed in the form of left ventricular end diastolic dimension (LVIDd), left ventricular end systolic dimension (LVIDs). LV dilatation was considered if the LVIDd or LVIDs as per BSA was above +2 Z-score. ${ }^{4}$ Systolic function assessment was based on Fractional Shortening (FS) and Ejection Fraction (EF), for which the normal values are: FS $28 \%$ to $44 \%$ and EF $56 \%$ to $78 \%$. The Tissue Doppler Imaging automatically measures $\mathrm{E}^{\prime} / \mathrm{A}^{\prime}$ ratio and reversal of $E^{\prime} / A^{\prime}$ ratio was considered as diastolic dysfunction. Myocardial performance index (MPI) which combines systolic and diastolic time intervals, has been described as an early, non-invasive and reproducible index for assessing combined LV function (normal range-0.2 to 0.4). Levothyroxine replacement therapy was started in all patients and dose was adjusted for age and weight. Out of 32, 29 patients were reviewed after 3 months for assessing response to therapy.

\section{Statistical Analysis}

Descriptive statistics of continuous variables were expressed as means and standard deviation. Discrete variables were presented as frequencies and group percentage. All continuous variables were tested for normal distribution by D'Agostino-Pearson normality test. Student's t-test was used to compare the means of continuous, normally distributed data. Categorical data were tested using the chi-square test. Wilcoxon Signed Rank Test was applied where data failed normality test and $\mathrm{t}$-value was replaced by Z-score. A p-value of less than 0.05 was considered statistically significant. Data were analysed using SPSS 17.0 software for Windows.

\section{RESULTS}

Of the 32 cases, $6(18.8 \%)$ were infants, 8 (25\%) were between 1 to 9 years and 18 (56.3\%) were between 10-15 years. Female preponderance $(68.8 \%$ females $)$ was noted.
Mean value of TSH and Free T4 were $205.58 \pm 267.33$ $\mu \mathrm{IU} / \mathrm{mL}$ and $0.67 \pm 0.37 \mathrm{ng} / \mathrm{dL}$ respectively. Hypothyroid appearance (coarse facies, dry skin, short stature) and exercise intolerance were present in 10 (31.3\%) cases, and pedal oedema and facial puffiness in 4 cases $(12.5 \%)$. In all these cases, TSH was above $50 \mu \mathrm{g} / \mathrm{mL}$. Bradycardia was noted in $12.5 \%$, tachycardia in 1 case (3.1\%), hypotension in $18.8 \%$ and hypertension in $3.1 \%$ cases (Figure 1). Mean systolic blood pressure was $92.56 \pm 10.97 \mathrm{mmHg}$ and the mean diastolic pressure was $61.53 \pm 6.85 \mathrm{mmHg}$. The mean value of $\mathrm{SpO}_{2}$ was $98.59 \pm 0.71 \%$. Dyslipidaemia was found in $22(68.75 \%)$ cases. Total cholesterol was raised in $16(50 \%)$ cases, raised LDL in 15 (46.9\%), raised triglycerides (TGA) in $9(28.1 \%)$, and high VLDL in $2(6.3 \%)$ cases whereas low HDL was observed in 5 (15.6\%). (Figure 2).

\begin{tabular}{|c|c|c|c|}
\hline Parameter & Group-A & Group-B & p-value \\
\hline Symptomatic & $5.3 \%$ & $69.2 \%$ & 0.0001 \\
\hline Hypotension & $5.3 \%$ & $38.5 \%$ & 0.0181 \\
\hline Bradycardia & 0 & $30.8 \%$ & 0.009 \\
\hline ECG abnormality & $36.8 \%$ & $100 \%$ & 0.0002 \\
\hline Echo abnormality & $63.2 \%$ & $100 \%$ & 0.01 \\
\hline Dyslipidaemia & $47.4 \%$ & $100 \%$ & 0.001 \\
\hline \multicolumn{4}{|c|}{ Table 1. Prevalence of Signs and Symptoms in } \\
Group A and Group B
\end{tabular}

\begin{tabular}{|c|c|c|c|}
\hline \multicolumn{2}{|c|}{ Parameters } & \multirow{2}{*}{$\begin{array}{c}\text { Mean } \pm \text { SD } \\
226.1 \pm 272.8\end{array}$} & \multirow{3}{*}{$\begin{array}{l}\mathrm{p} \text {-value } \\
<0.001\end{array}$} \\
\hline \multirow{2}{*}{$\mathrm{TSH}(\mu \mathrm{IU} / \mathrm{mL})$} & Baseline & & \\
\hline & 3 months & $3.72 \pm 4.39$ & \\
\hline \multirow{2}{*}{ FT4 (ng/dL) } & Baseline & $0.66 \pm 0.38$ & \multirow{2}{*}{$<0.001$} \\
\hline & 3 months & $1.6 \pm 1.51$ & \\
\hline \multirow{2}{*}{$\begin{array}{l}\text { Heart rate } \\
\text { (per min.) }\end{array}$} & Baseline & $86.2 \pm 19.1$ & \multirow{2}{*}{0.0003} \\
\hline & 3 months & $96.24 \pm 13.3$ & \\
\hline \multirow{2}{*}{$\begin{array}{c}\text { Systolic BP } \\
\text { (mmHg) }\end{array}$} & Baseline & $91.4 \pm 10.1$ & \multirow{2}{*}{$<0.001$} \\
\hline & 3 months & $95.5 \pm 8.5$ & \\
\hline \multirow{2}{*}{ PR (sec) } & Baseline & $0.17 \pm 0.03$ & \multirow{2}{*}{$<0.001$} \\
\hline & 3 months & $0.14 \pm 0.01$ & \\
\hline \multirow{2}{*}{ QTc (sec) } & Baseline & $0.44 \pm 0.04$ & \multirow{2}{*}{$<0.001$} \\
\hline & 3 months & $0.41 \pm 0.02$ & \\
\hline \multirow{2}{*}{$\begin{array}{c}\text { Cholesterol } \\
(\mathrm{mg} / \mathrm{dL})\end{array}$} & Baseline & $237.5 \pm 78.2$ & \multirow{2}{*}{$<0.001$} \\
\hline & 3 months & $166.7 \pm 11.7$ & \\
\hline \multirow{2}{*}{ TGA (mg/dL) } & Baseline & $176 \pm 81.7$ & \multirow{2}{*}{0.014} \\
\hline & 3 months & $146.9 \pm 14.8$ & \\
\hline \multirow{2}{*}{$\mathrm{LDL}(\mathrm{mg} / \mathrm{dL})$} & Baseline & $136.7 \pm 63.9$ & \multirow{2}{*}{$<0.001$} \\
\hline & 3 months & $72 \pm 10$ & \\
\hline \multirow{2}{*}{ HDL (mg/dL) } & Baseline & $55.5 \pm 12.6$ & \multirow{2}{*}{$<0.001$} \\
\hline & 3 months & $61.5 \pm 2.7$ & \\
\hline \multirow{2}{*}{ VLDL $(\mathrm{mg} / \mathrm{dL})$} & Baseline & $27.4 \pm 19.3$ & \multirow{2}{*}{0.24} \\
\hline & 3 months & $22.4 \pm 6.2$ & \\
\hline \multirow{2}{*}{ LVIDd-Z score } & Baseline & $0.23 \pm 1.82$ & \multirow{2}{*}{0.058} \\
\hline & 3 months & $-0.27 \pm 0.96$ & \\
\hline \multirow{2}{*}{ LVIDs-Z score } & Baseline & $0.41 \pm 1.5$ & \multirow{2}{*}{0.17} \\
\hline & 3 months & $0.1 \pm 0.98$ & \\
\hline \multirow{2}{*}{ LVPW-Z score } & Baseline & $2.01 \pm 2.3$ & \\
\hline & 3 months & $0.53 \pm 0.8$ & $<0.001$ \\
\hline JVS-7 score & Baseline & $2.31 \pm 2.16$ & $0 \cap 001$ \\
\hline IVs-L score & 3 months & $0.57 \pm 0.85$ & 0.0001 \\
\hline FS $1 \%$ & Baseline & $36.28 \pm 5.53$ & 0.8 \\
\hline FS (\%) & 3 months & $36.55 \pm 4.9$ & 0.8 \\
\hline FF (0\%) & Baseline & $64.97 \pm 6.8$ & 073 \\
\hline EF (\%) & 3 months & $64.55 \pm 5.04$ & 0.13 \\
\hline MPI & Baseline & $0.35 \pm 0.07$ & 0.04 \\
\hline MIPI & 3 months & $0.32 \pm 0.03$ & 0.04 \\
\hline
\end{tabular}




\section{ECG Changes}

The most common abnormality observed was prolonged PR interval in 14 (43.8\%) cases. Prolonged QTc was observed in 12 (37.5\%), low voltage complexes were noted in 11 (34.4\%), flat T-wave in $7(21.9 \%)$ cases. The mean PR interval was $0.17 \pm 0.03$ seconds and the mean QTc interval was $0.44 \pm$ 0.04 seconds. P-axis and QRS-axis were within normal range in all the cases. According to ECG, 4 (12.5\%) had bradycardia, while only 1 had tachycardia and 27 patients had a normal heart rate. (Figure-3) Mean heart rate was $85.47 \pm 18.41$ beats per minute.

\section{D-Echocardiography/Colour Doppler}

The most common echocardiographic finding was septal hypertrophy, seen in 16 (50\%) cases, followed by LV posterior wall hypertrophy (LVPW) in $14(43.8 \%)$ and LV dilatation in $8(25 \%)$ cases. Pericardial effusion was present in $8(25 \%)$ cases, tricuspid regurgitation in $3(9.37 \%)$ and 4 $(12.5 \%)$ cases had cardiac dysfunction of which 1 patient had only diastolic dysfunction and rest 3 had combined systolic and diastolic dysfunction. (Figure-4).

On correlating the cardiovascular parameters with Thyroid hormone levels, it was noted that children with more than $50 \mu \mathrm{g} / \mathrm{mL}$ of TSH were significantly symptomatic with signs of hypotension and bradycardia, had altered laboratory parameters: dyslipidaemia with statistically significant ECG and 2D Echocardiography abnormalities. (Figure-5).

\section{Months follow-up}

Out of 32, 29 patients followed up after 3 months of thyroxine therapy. 28 patients were euthyroid on follow-up, whereas 1 patient persisted in having high TSH value $(25 \mu \mathrm{IU} / \mathrm{mL})$ due to poor compliance. This patient persisted to have prolonged QTc interval, hypertension, prolonged PR and QTc interval. In our study, the mean free T4 level of $0.66 \pm 0.38 \mathrm{ng} / \mathrm{dL}$ in 29 cases increased to $1.6 \pm 1.51 \mathrm{ng} / \mathrm{dL}$ and the mean TSH level of $226.12 \pm 272.87 \mu \mathrm{IU} / \mathrm{mL}$ decreased to $3.72 \pm 4.39 \mu \mathrm{IU} / \mathrm{mL}$ after 3 months treatment which was statistically significant. The signs and symptoms improved and the echocardiographic and lipid levels normalised in all the patients. ECG abnormalities also normalised except in one patient. Systolic blood pressure increased significantly from $91.47 \pm 10.14 \mathrm{mmHg}$ to $95.52 \pm 8.50 \mathrm{mmHg}$ post therapy. Heart rate on electrocardiography showed significant improvement from $86.21 \pm 19.19$ beats per minute to $96.24 \pm$ 13.30 beats per minute and PR and QTc interval showed a statistically significant decrease post therapy ( $p$-value $<0.001$ ). LVIDd Z-score, LVIDs Z-score, fraction shortening, ejection fraction did not show a significant difference post therapy. However, MPI (p-value 0.042), LVPW Z-score (pvalue $<0.001$ ) and IVS Z-score ( $p$-value $<0.001$ ) significantly decreased after therapy. In our study, there was a statistically significant decrease in total cholesterol, triglycerides and LDL-C levels and a significant increase in HDL-C levels (Table-2).

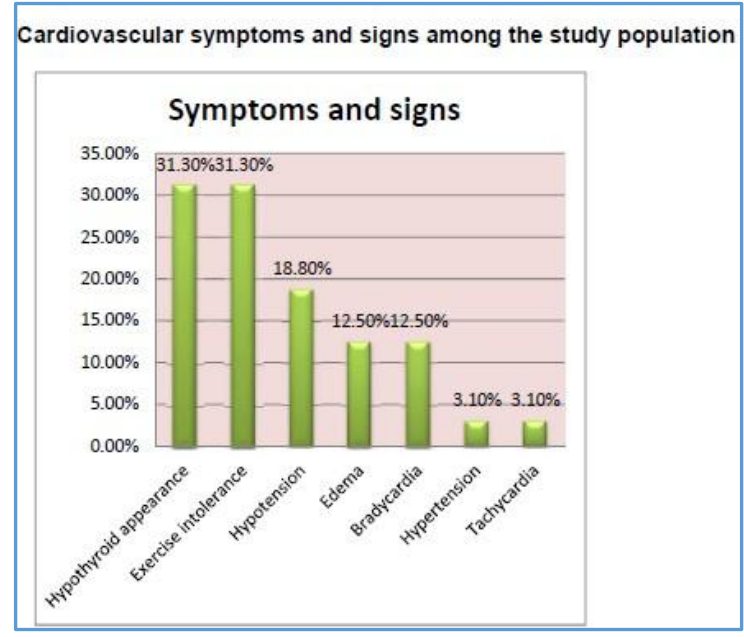

Figure-1. Cardiovascular Symptoms and Signs among the Study Population

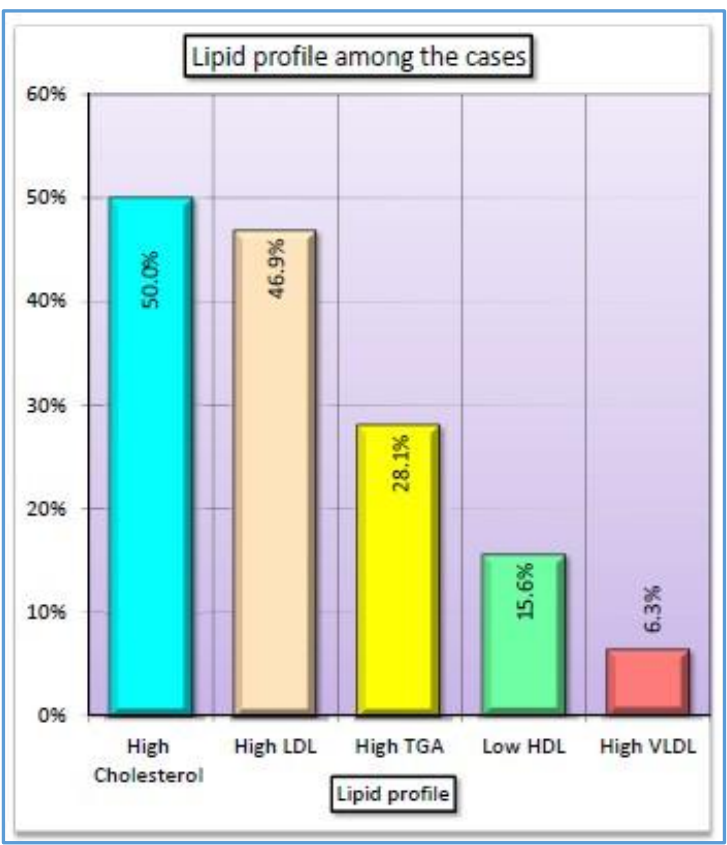

Figure-2. Lipid Profile pattern in Hypothyroid Cases

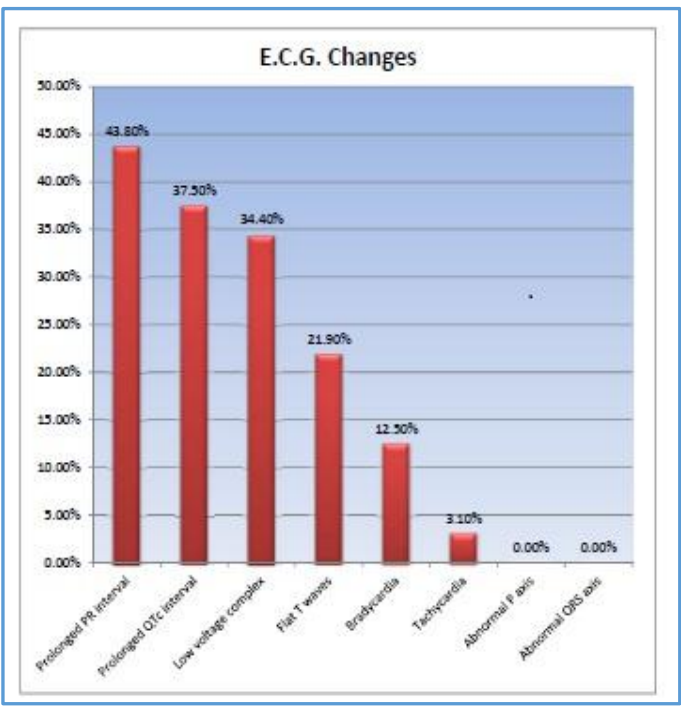

Figure 3. E.C.G changes in Hypothyroid Cases 


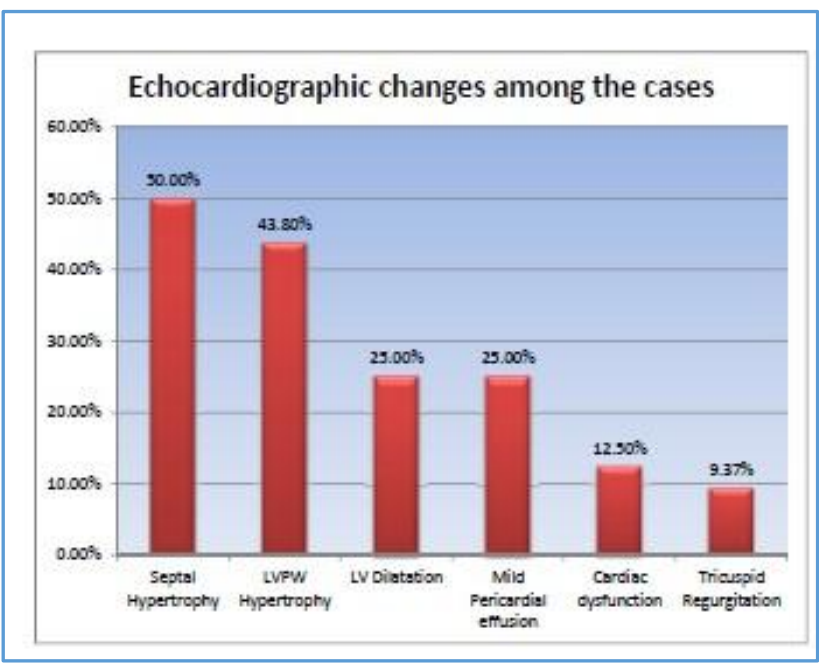

Figure 4. Echocardiographic changes among Cases.

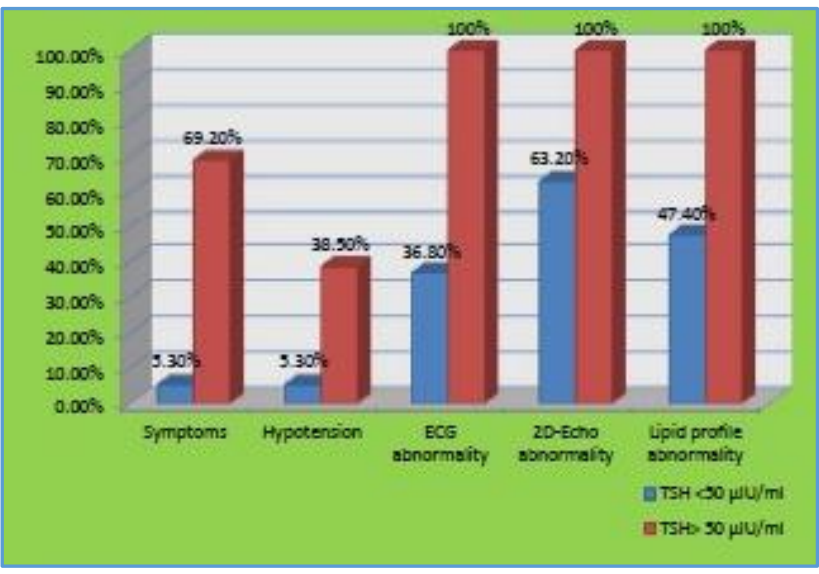

Figure 5. Comparison of various Parameters between Group A and Group B.

\section{DISCUSSION}

Hypothyroidism is a clinical syndrome ensuing from an insufficiency of thyroid hormones, which leads to a generalised slowdown of metabolic processes. Hypothyroidism has a wide clinical spectrum ranging from a frank state of myxoedema, end-organ impact and multisystem failure to an asymptomatic subclinical state. In the present study, 32 hypothyroid infants and children from Day 4 to 15 years of age were studied during June 2012 November 2013, data analysis is done and discussed here in comparison with previous trials. Most patients belonged to the age between 10 to 15 years with an overall female preponderance (68.8\%). Other studies also reported that hypothyroidism was more prevalent among females than males. ${ }^{5}$

Usual symptoms may include exertional dyspnoea, cold intolerance and fatigue. Bradycardia and systemic hypertension, with narrow pulse pressure and slightly increased mean arterial pressure, and some degree of exercise impairment are the most common findings in patients with overt hypothyroidism. 6 In this study, hypothyroid appearance (coarse facies, dry skin, short stature) was prevalent with high TSH (above $50 \mu \mathrm{g} / \mathrm{mL}$ ) along with exercise intolerance, pedal oedema and puffiness of the face. Inadequate skeletal muscle blood flow compromises exercise capability via diminished $\mathrm{O}_{2}$ transport and stamina, through decreased supply of blood-borne substrates which was supported by McAllister RM et al. ${ }^{7}$

\section{Blood Pressure}

The individuals with mild-to-moderate hypothyroidism usually have an increased possibility of developing hypertension, particularly diastolic hypertension, while individuals with severe hypothyroidism are more likely to have normal or slightly low blood pressure. ${ }^{8}$ The two factors contributing to systemic hypertension are the remarkable increase in peripheral vascular resistance and increase in arterial stiffness, which is likely to result from myxoedema of the arterial wall. Bergus et $\mathrm{al}^{9}$ study in geriatric population did not show any association between hypertension and hypothyroidism. In our study, blood pressure was normal in 25 cases; however, 6 (18.8\%) patients presented with hypotension and only 1 patient had hypertension. Hypotension may occur in hypothyroidism, although not as commonly as hypertension. Thompson et al ${ }^{10}$ could induce hypotension by inducing hypothyroidism after dietary administration of propylthiouracil to male Sprague-Dawley rats for a period of 8 weeks. Brown et al ${ }^{11}$ also observed a small but significant decrease in systolic blood pressure in patients who had undergone thyroidectomy for thyroid cancer.

\section{Lipid Profile}

Hypothyroidism accounts for about $2 \%$ of all cases of hyperlipidaemia and is second only to diabetes mellitus as a cause of secondary hyperlipidaemia. 5 Many studies have found a significant correlation between raised TSH levels and serum total cholesterol and LDL cholesterol. Dyslipidaemias are major causes of increased atherogenic risk. Our findings correlate with the results of other authors who have stated that hypercholesterolaemia and a marked increase of LDL-C are typically found in hypothyroid individuals. $5,12,13$ It is an established fact that the transcription of the HMG-CoA reductase gene gets triggered by thyroid hormones. As HMGCoA reductase is the rate-limiting enzyme in the cholesterol synthesis pathway, reduced cholesterol synthesis is likely in hypothyroidism. Nonetheless, LDL-receptor gene is also one of the target genes for thyroid hormone. Though cholesterol synthesis is compromised in hypothyroid state, this effect is overcome by a significantly reduced fractional clearance of LDL particles due to decreased number of LDL receptors in the hepatocytes, leading to LDL accumulation in blood and causing high serum TC and LDL-C levels. Inconsistent results were found in different studies regarding HDL levels in hypothyroidism. Radonjic et al ${ }^{12}$ observed that HDL-C levels were considerably reduced in the patients in the oldest group (15 to 18 years). Verdugo et $\mathrm{al}^{14}$ found normal HDL-C levels in hypothyroid women, Agdeppa et al ${ }^{15}$ observed lower concentrations in hypothyroidism, whereas the higher HDL-C values were reported in other studies. ${ }^{16} \mathrm{~A}$ decrease in lipoprotein lipase activity is found in overt hypothyroidism, with decreasing the clearance of TG-rich lipoproteins. This causes an elevated TG and VLDL level as seen in our case which is similar to the findings of other authors.13,17

\section{Electrocardiography}

In the present study, electrocardiographic abnormalities were present in 20 out of $32(62.5 \%)$ children. The most 
common abnormality observed was prolonged PR interval which results from conduction delay in the atrium, atrioventricular node, and/or His-Purkinje system. Multiple mechanisms have been postulated: circulatory insufficiency due to restrictive lesions in the vessels supplying the nodal and conduction tissue, histologic changes in the conduction system, compression of the conduction system by surrounding interstitial oedema, suppression of direct stimulatory effect of thyroid hormone on the nodal and conduction tissue, or suppression of epinephrine effect on the conduction mechanism in hypothyroidism. PR-prolongation is not a common finding in many similar studies but has been reported by Cheng et $\mathrm{al}^{18}$ and Luten et $\mathrm{a}^{19}$ in the past. Many patients with overt hypothyroidism have QTc interval lengthening which reflects the prolonged cardiac action potential. ${ }^{6}$ Bradycardia was seen in $12.5 \%$ cases in our study and is in agreement with other studies by Sharath et al ${ }^{13}$ and Nikoo et al. ${ }^{8}$ Sinus tachycardia, although rare has been reported in the literature by Nikoo et al and was also noted in 1 of our cases. The $\mathrm{T}$ wave may be flattened or inverted in several leads but we found flattened T-waves only.

\section{Echocardiography}

As a non-invasive method echocardiography can play important role in recognising the cardiac pathology as well as to follow up the effect of the therapy. In the present study, the most common echocardiographic finding was septal hypertrophy in $16(50 \%)$ cases, followed by LV posterior wall hypertrophy (LVPW)(43.8\%). Both Farooki et al ${ }^{20}$ and Altman et $\mathrm{al}^{21}$ found asymmetrical septal hypertrophy in hypothyroid children. Rawat et $\mathrm{al}^{22}$ showed the relatively increased thickness of IVS and LVPW as compared to control subjects. Dilated cardiomyopathy secondary to hypothyroidism has been reported by many authors e.g. Kota et $\mathrm{al}^{23}$ and Khochtali et al. ${ }^{24}$ In our study, mild LV dilatation was seen in 8 cases in both the groups.

In hypothyroidism, pericardial fluid accumulates slowly, in most cases, allowing stretching of the pericardium, accommodating a large volume. The pathogenesis of pericardial effusion in hypothyroid patients is probably due to the increased systemic capillary permeability and disturbances in electrolyte metabolism. ${ }^{25}$ Pericardial effusion was seen in $8(25 \%)$ cases and was mild in all the 8 cases in our study. Fouron et al $^{26}$ pointed out the significantly low incidence of pericardial effusion in young patients. Rawat et $\mathrm{al}^{22}$ study showed no pericardial effusion in patients younger than 30 years whereas Bhupathi et $\mathrm{al}^{27}$ in their study in paediatric hypothyroid cases, found a high incidence of pericardial effusion (50\%).

Left ventricular (LV) diastolic dysfunction, which is characterised by slower myocardial relaxation and impaired early ventricular filling is a common occurrence in hypothyroidism. LV systolic function is only marginally subnormal. But in our study cardiac dysfunction was present in 4 cases $(12.5 \%)$ out of which 1 patient had diastolic dysfunction and rest 3 had combined systolic and diastolic dysfunction. Subtle diastolic and systolic dysfunction was also a finding by Bhupathi et al. ${ }^{27}$ Tricuspid regurgitation is a common finding of hyperthyroidism and not hypothyroidism but it has been reported with severe hypothyroidism by Seol et al. 28

\section{Correlation to Thyroid Hormone Levels}

Symptoms, signs, lipid abnormalities, electrocardiographic abnormalities, and echocardiographic abnormalities were related to TSH levels and prevalence was significantly higher with high TSH values (TSH more than $50 \mu \mathrm{IU} / \mathrm{mL}$ ). Tehrani et al $^{29}$ also observed a positive significant correlation between serum level of TSH and diastolic blood pressure. Nathaniel et $\mathrm{al}^{30}$ reported that the degree of the QTc prolongation was directly related to the severity of hypothyroidism. Radonjic et al(12) obtained good correlation between cholesterol and TSH values as well as between the LDL-C and TSH values.

\section{Response to Therapy}

Thyroxine therapy reverses all the cardiovascular changes associated with hypothyroidism as was seen in many studies in the past.12, 22, 23, 27, 28 In this study, symptoms and signs improved with the achievement of euthyroidism in the form of disappearance of oedema, a decrease in weight and BMI, gain in height and normalisation of pulse rate and blood pressure. There was a statistically significant improvement in systolic blood pressure, ECG (PR and QTc interval), dyslipidaemia (cholesterol, triglycerides, LDL and HDL) and echocardiography (MPI, LVPW, and IVS).

\section{CONCLUSION}

Children with hypothyroidism have significant cardiovascular abnormalities which are proportionally related to TSH value and these changes are completely reversible with treatment. Hence, early diagnosis with optimal treatment reduces the cardiac morbidity in these children. The presence of hypotension in this study potentiates the need for further research in a larger number of paediatric subjects.

\section{REFERENCES}

[1] Fazio S, Palmieri EA, Lombardi G. Effects of thyroid hormone on the cardiovascular system. Recent Prog Horm Res 2004;59:31-50.

[2] Klein I, Ojamaa K. Thyroid hormone and the cardiovascular system. N Engl J Med 2001;344(7):5019.

[3] Lopez L, Colan SD, Frommelt PC, et al. Recommendations for quantification methods during the performance of a pediatric echocardiogram: a report from the pediatric measurements writing group of the American society of echocardiography pediatric and congenital heart disease council. J Am Soc Echocardiogr 2010;23(5):465-95.

[4] Kampmann C, Wiethoff C, Wenzel A, et al. Normal values of M mode echocardiographic measurements of more than 2000 healthy infants and children in central Europe. Heart 2000;83(6):667-72.

[5] Saxena A, Kapoor P, Saxena S, et al. Effect of levothyroxine therapy on dyslipidemia in hypothyroid patients. Internet Journal of Medical Update 2013;8(2):39-49.

[6] Klein I, Ojamaa K. The cardiovascular system in hypothyroidism. In: Braverman LE, Utiger RD, (eds). Werner \& Ingbar's the thyroid: a fundamental and clinical text. $8^{\text {th }}$ edn. Philadelphia: Lippincott Williams \& Wilkins, 2000:777-82. 
[7] McAllister RM, Delp MD, Laughlin MH. Thyroid status and exercise tolerance. Cardiovascular and metabolic considerations. Sports Med 1995;20(3):189-98.

[8] Nikoo MH. Cardiovascular manifestations of hypothyroidism. Shiraz E Medical Journal 2001;2(1):710.

[9] Bergus GR, Mold JW, Barton ED, et al. The lack of association between hypertension and hypothyroidism in a primary care setting. J Hum Hypertens 1999;13(4):231-5.

[10] Brown RT, Lakshmanan MC, Baucom CE, et al. Changes in blood pressure and plasma noradrenaline in shortterm hypothyroidism. Clinical Endocrinology 1989;30(6):635-8.

[11] Najjar SS, Nassif SI. Congestive heart failure in infancy due to hypothyroidism. Acta Paediatr 1963;52(3):31926.

[12] Vesna R, Zorana JV, Slavica S, et al. Serum lipids in hypothyroid children: effect of disease and levothyroxine replacement therapy. Jugoslov Med Bio Chem 2002;21(4):331-8.

[13] Shah SKD, Kilari M, Shah NKS. Cross sectional study of cardiovascular manifestations of hypothyroidism. Journal of Evolution of Medical and Dental Sciences 2013;2(27):5021-9.

[14] Verdugo C, Perrot L, Ponsin G, et al. Time-course of alterations of high-density lipoproteins (HDL) during thyroxine administration to hypothyroid women. Eur J Clin Invest 1987;17(4):313-6.

[15] Agdeppa D, Macaron C, Mallik T, et al. Plasma highdensity lipoprotein cholesterol concentration in thyroid disease. J Clin Endocrinol Metab 1979;49(5):726-9.

[16] Friis T, Pedersen LR. Serum lipids in hyper-and hypothyroidism before and after treatment. Clin Chim Acta 1987;162(2):155-63.

[17] Rizos CV, Elisaf MS, Liberopoulos EN. Effects of thyroid dysfunction on lipid profile. Open Cardiovasc Med J 2011;5:76-84.

[18] Cheng S, Keyes MJ, Larson MG, et al. Long-term outcomes in individuals with prolonged PR interval or first-degree atrioventricular block. JAMA 2009;301(24):2571-7.
[19] Fredlund BO, Olsson SB. Long QT interval and ventricular tachycardia of "torsade de pointe" type in hypothyroidism. Acta Med Scand 1983;213(3):231-5.

[20] Farooki ZQ, Hoffman WH, Perry BL, et al. Myocardial dysfunction in hypothyroid children. Am J Dis Child 1983;137(1):65-8.

[21] Altman DI, Murray J, Milner S, et al. Asymmetric septal hypertrophy and hypothyroidism in children. Br Heart J 1985;54(5):533-8.

[22] Rawat B, Satyal A. An echocardiographic study of cardiac changes in hypothyroidism and response to treatment. Kathmandu Univ Med J 2004;2(3):182-7.

[23] Kota KS, Ranjan P, Kota SK, et al. Primary hypothyroidism: uncommon presentation with reversible dilated cardiomyopathy in a young subject. Int J Endocrinol Metab 2012;10(1):440-3.

[24] Khochtali I, Hamza N, Harzallah O, et al. Reversible dilated cardiomyopathy caused by hypothyroidism. Int Arch Med 2011;4:20.

[25] Chou SL, Chern $\mathrm{CH}$, How CK, et al. A rare case of massive pericardial effusion secondary to hypothyroidism. J Emerg Med 2005;28(3):293-6.

[26] Fouron JC, Bourgin JH, Letarte J, et al. Cardiac dimensions and myocardial function of infants with congenital hypothyroidism: an echocardiographic study. Br Heart J 1982;47(6):584-7.

[27] Bhupathi R, Kothari SS, Gupta AK, et al. Cardiac function in hypothyroid children: effect of replacement therapy. Indian Pediatr 1999;36(8):77984.

[28] Seol SH, Kim DI, Park BM, et al. Complete atrioventricular block presenting with syncope caused by severe hypothyroidism. Cardiol Res 2012;3(5):23941.

[29] Tehrani FR, Tohidi M, Dovom MR, et al. A populationbased study on the association of thyroid status with components of the metabolic syndrome. J Diabetes Metab 2011;2(8):156-68.

[30] Nathaniel C, Caleb L, Azrin MA. QTc prolongation in hypothyroidism. J Am Coll Cardiol 1994;23:36A. 